\title{
The integration of JERS-1 and ERS SAR in differential interferometry for measurement of complex glacier motion
}

\author{
Xiao $\mathrm{CHENG}^{1}$ Guanhua $\mathrm{XU}^{2}$ \\ ${ }^{1}$ State Key Laboratory of Remote Sensing Science, Institute of Remote Sensing Applications of Chinese Academy of Sciences \\ and Beijing Normal University, PO Box 9718, Beijing 100101, China \\ E-mail: xcheng@irsa.ac.cn \\ ${ }^{2}$ Chinese Ministry of Science and Technology, Beijing, China
}

\begin{abstract}
Complex glacier motion in the Grove Mountains region, Antarctica, is measured using fourpass differential synthetic aperture radar (SAR) interferometry (InSAR). The components of the motion vector field are resolved using a 44 day-separation Japanese Earth Resources Satellite-1 (JERS-1) InSAR pair and a European Remote-sensing Satellite-1/-2 (ERS-1/-2) tandem InSAR pair. The 44 day temporal baseline provides the sensitivity required to observe the range of ice motion (around 8-10 $\mathrm{m} \mathrm{a}^{-1}$ ), and the 1 day short baseline provides the best choice for glacier digital elevation model reconstruction. It is remarkable that the scattering field of the JERS-1 pair remained coherent over the long time interval and the interferometric fringes are clear. The overall ice flow is from east to west, downslope and towards Lambert Glacier. The regional flow is obstructed by nunataks extending north-south, with two wide gaps. Two narrow glaciers flow past the nunataks and rejoin each other at the downstream end. Regional morphology, and the resolved flow in the Grove Mountains area, suggests that ice flow is channeled throughout this eastern flank of Lambert Glacier.
\end{abstract}

\section{INTRODUCTION}

Ice-flow velocity is a fundamental measurement for the study of ice dynamics. Even with the advent of the global positioning system (GPS), in situ velocity measurement remains an expensive, difficult and often dangerous task that is capable of yielding only a limited number of measurements over isolated sites. It is particularly difficult to carry out in situ velocity measurements in the remote polar regions.

Satellite imagery is naturally suitable for studying polar regions and other remote places. Cross-correlation of sequential optical images can be used to measure the iceflow velocity (Scambos and others, 1992; Scambos and Bindschadler, 1993; Bindschadler, 1998), but is limited due to the long polar night, frequent cloud cover and featureless ice surface.

Imaging radars are more suitable for research on glaciers because of their all-weather capability. Synthetic aperture radar (SAR) interferometry (InSAR) has now become a wellestablished means of collecting ice velocity measurements at high resolution and with high accuracies. Goldstein and others (1993) were the first to estimate glacier motion using InSAR. They used European Remote-sensing Satellite-1 (ERS-1) data to estimate the speed of Rutford Ice Stream, Antarctica, in a rather flat region. Since then, many studies have applied InSAR successfully to a variety of glacier targets in Antarctica, Greenland and the European Alps (Joughin and others, 1995, 1996; Kwok and Fahnestock, 1996; Cumming and others, 1997; Wangensteen and others, 1999; Kwok and others, 2000; Anja and others, 2004). Most of these studies used data from the ERS-1 and -2 SAR sensors.

In September 1997, RADARSAT was maneuvered to a south-facing orientation to collect complete coverage of Antarctica during the Antarctic Mapping Mission (AMM-1). AMM-1 is also known as the 'RAMP mosaic' (where RAMP stands for RADARSAT Antarctic Mapping Project). The
Modified Antarctic Mapping Mission (AMM-2) occurred during the boreal fall of 2000. The acquisition strategy concentrated on collecting highest-resolution RADARSAT data of Antarctica's fast glaciers for change detection and feature-retracking estimates of surface velocity (Jezek, 2002).

Though AMM-1 and AMM-2 provided a wealth of data, some signal coherence was lost through temporal decorrelation over the 24 day InSAR repeat interval for fast motion. Gray and others (1998) developed an alternative to the standard InSAR technique called speckle tracking, which relies on interferometic correlation to obtain surface motion (Joughin and others, 1999; Young and Hyland, 2002). However, the lower precision of this technique $\left(\sim 5 \mathrm{~m} \mathrm{a}^{-1}\right)$ makes it a coarser tool, and it is still not a global solution.

The SAR sensors on board ERS-1/-2 and RADARSAT operate at $C$ band $\left(\lambda_{\text {ERS }}=5.7 \mathrm{~cm}\right)$, while Japanese Earth Resources Satellite-1 (JERS-1) SAR operates at $\mathrm{L}$ band $(\lambda=23.5 \mathrm{~cm})$. JERS-1 SAR also has high potential for monitoring ice-sheet and glacier movement, but poor orbit information has constrained its usefulness. Ozawa and others (1999) used JERS-1 data to generate a digital elevation model (DEM) of the Syowa station coastal area, but no report of Antarctic ice flow measurement using JERS-1 InSAR has been found to date.

Our objective is to measure the complex ice-velocity field over the Grove Mountains area by integrating the L-band and C-band InSAR data. The effects of the nunataks on ice motion will be briefly examined.

\section{STUDY AREA AND DATASETS}

The Grove Mountains $\left(72^{\circ} 45^{\prime} \mathrm{S}, 75^{\circ} 00^{\prime} \mathrm{E}\right)$ is the name given to a large, scattered group of mountains and nunataks extending over an area approximately 60 by $30 \mathrm{~km}$, located $160 \mathrm{~km}$ east of Mawson Escarpment and $400 \mathrm{~km}$ south of the Chinese Zhongshan station in East Antarctica. It was first photographed from the air by aircraft of the US Navy 


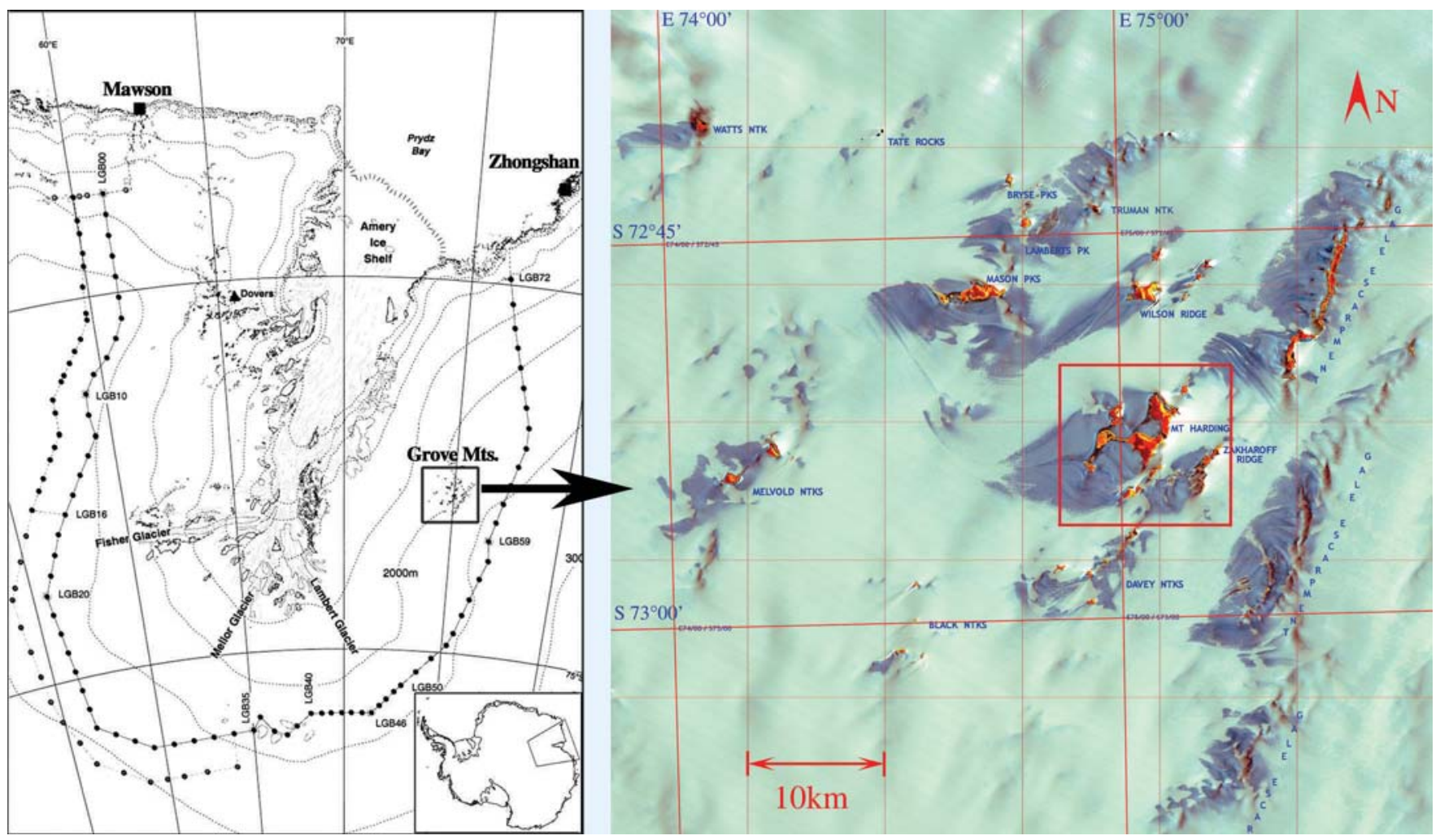

Fig. 1. TM pseudo-color imagery of the Grove Mountains and the location in Lambert Glacier and Antarctica. The Grove Mountains are on the eastern flank of Lambert Glacier.

Operation Highjump in 1946-47. It was named by the Antarctic Names Commission of Australia for Squadron Leader I.L. Grove, a Royal Air Force pilot who flew with the Australian National Antarctic Research Expeditions (ANARE) in 1958 (Alberts, 1995).

A Landsat Thematic Mapper (TM) pseudo-color image of the Grove Mountains is shown in Figure 1. The image indicates that nunataks are widely distributed here. Also noticeable are the blue-ice features around or on the left (western) side of the nunataks. The Grove Mountains are a meteorite trap, and in recent years Chinese researchers have found nearly 4500 meteorites on the blue-ice field. A RAMP interferometry and speckle-matching result (Joughin, 2002) indicates that the velocity of ice flow in the Grove Mountains is $<10 \mathrm{ma}^{-1}$, which is much slower than the glacier flow beyond their north and south borders. This slow velocity is caused by the nunataks and mountains that impede ice flow. However, since the nunataks are separated, the ice sheet must flow through in some specific way. Because the ice flow is complicated and the weather is harsh, it is impossible to measure large-area flow velocities using traditional surveying methods.

The Grove Mountains were unexplored until the 1970s, when Australian researchers flew there by helicopter. Chinese researchers visited them during the 1998/99, 1999/2000 and 2002/03 austral summer seasons. Chinese surveyors mapped the core region of Mount Harding in Grove Mountains at the scale of $1: 25000$ using a postprocessing differential GPS method. The core region marked in Figure 1 with a quadrangle covers about $110 \mathrm{~km}^{2}$. Besides the GPS DEM, existing low-resolution DEM data in this area include US Geological Survey GTOPO 30 DEM (30') and RAMP DEM (200 m).
The Grove Mountains were imaged on 25 March, 21 June and 4 August 1996 by JERS-1 SAR with $\mathrm{HH}$ polarization. Analysis shows that the interferometric combination of the later two images is the best because of the shorter temporal (44 day) and perpendicular (148 m) baselines.

Also available are three ERS-1/-2 images acquired on 10 and 11 February and 16 March 1996 during the ERS tandem mission, and several scenes of RADARSAT SAR images acquired in RAMP. The tandem ERS pair has good correlation and appropriate phase gradient. RADARSAT data were not used since the data were not available to the authors.

Out of these, one 44 day JERS-1 InSAR pair and one ERS-1/-2 tandem InSAR pair have sufficient scene coherence in the study area, as detailed in Table 1. Using the two InSAR pairs, we assessed the ability of four-pass differential interferometry with SAR data acquired at different bands to monitor glacier motion.

The high-resolution GPS DEM $(1: 25000)$ of the core region and the RAMP DEM for the whole area were also used.

\section{METHODS}

\section{SAR interferometry}

Neglecting the influences of noise and atmosphere, the interferometric phase $\phi$ measured by InSAR on the surface of a moving ice sheet consists of two components:

$$
\phi=\phi_{\text {topography }}+\phi_{\text {displacement }},
$$

where $\phi_{\text {topography }}$ denotes the phase due to a varying topography and $\phi_{\text {displacement }}$ denotes phase due to ice motion. 


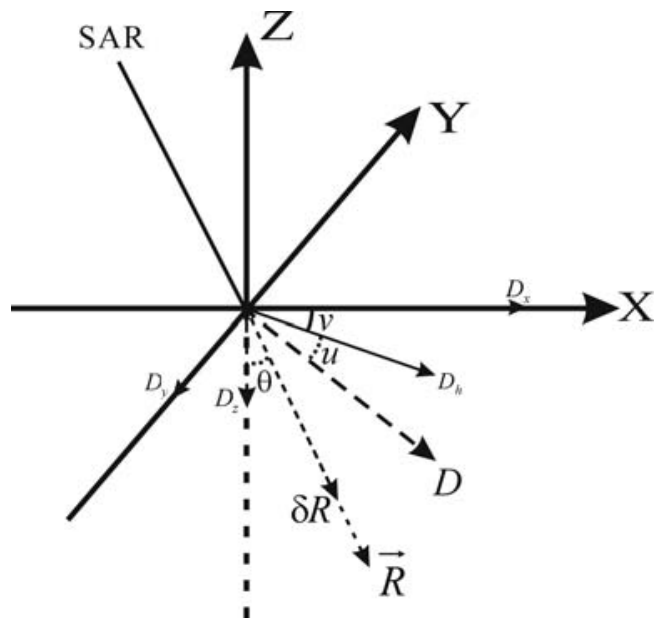

Fig. 2. Diagram showing the surface displacement, $D$, and the InSAR-measured LOS displacement $\delta R . x, y$ and $z$ are ground range, radar azimuth and zenith directions, respectively. LOS is in the $x-z$ plane for SARs that are processed close to zero Doppler. $\delta R$ is in the direction of radar LOS. The incidence angle, $\theta$, is measured with respect to local zenith, $u$ is the angle between $D$ and the $x-y$ plane, and $v$ is the angle between $D_{\mathrm{h}}$ and $x$.

The relative height change corresponding to a $2 \pi$ phase difference is defined as HA (height ambiguity):

$$
\mathrm{HA}=\lambda R \sin \theta /\left(2 B_{\mathrm{n}}\right),
$$

where $\lambda$ is the wavelength, $R$ is the slant range from the first antenna to the ground point, $\theta$ is the incidence angle and $B_{\mathrm{n}}$ is the perpendicular component of the baseline. Shorter $B_{\mathrm{n}}$ or longer $\lambda$ correspond to larger HA. It is obvious that HA of the JERS-1 ( $\mathrm{L}$ band) is larger than that of ERS InSAR ( $\mathrm{C}$ band) when the lengths of $B_{\mathrm{n}}$ are the same.

The phase term associated with the change in range adds directly into the interferometric phase as a motion phase:

$$
\phi_{\text {displacement }}=-\frac{4 \pi}{\lambda} \delta R=-\frac{4 \pi}{\lambda} v_{\mathrm{s}} \Delta T,
$$

where $\delta R$ is the amount of line-of-sight (LOS) motion towards the radar that occurs between two observations, $v_{\mathrm{s}}$ is the LOS component of ice-flow velocity and $\Delta T$ is the time between two observations. The value of LOS displacement causing a $2 \pi$ phase difference is $\lambda / 2$ and is defined as $\mathrm{SD}$ (sensitivity to displacement). So InSAR is highly sensitive to deformations with measurements at centimeter (L-band) or sub-centimeter (C-band) level.

The topographic phase should first be removed from the total phase to obtain the pure motion phase. Four-pass differential InSAR (DInSAR) requires two pairs of SAR images from repeat passes of a SAR satellite over the area of interest. One pair is used to generate a DEM which contains the topographic information. The other pair, referred to as a targeting pair, is used to identify the possible or expected ground deformation that occurred between the two acquisitions. The InSAR DEM is used to remove the topographic phase contributions from the interferogram of the targeting pair, so that changes of ground surface can be detected (Hanssen, 2001).

\section{Flow estimation}

The velocity of ice flow is a three-dimensional vector field. However, side-looking InSAR detects only the LOS component of ice flow. To map surface-parallel flow, we modified the procedure of Mattar and others (1998). As shown in Figure 2, the relationship between surface displacement $D\left(D_{x}, D_{y}, D_{z}\right)$ and the LOS measurement $\delta R$ can be given as:

$$
\begin{aligned}
\delta R & =D(\cos u \cos v \sin \theta+\sin u \cos \theta) \\
& =D_{\mathrm{h}} \cos v \sin \theta+D_{z} \cos \theta \\
& =D_{x} \sin \theta+D_{z} \cos \theta
\end{aligned}
$$

where $D_{\mathrm{h}}$ is the motion projected onto the plane tangent to the surface of the ellipsoid, $D_{x}$ and $D_{y}$ are defined on the range and azimuth directions, respectively, $D_{z}$ is the vertical component, and $u$ and $v$ are the angles shown in Figure 2.

The derivative of $D$ varies with respect to both $u$ and $v$. As $u$ and $v$ approach their critical values, $\delta R$ becomes less sensitive to $D$ and $D$ becomes increasingly sensitive to errors in $u$ and $v$. The root-mean-square error of $D$ increases proportionately as the errors in $u$ and $v$ increase. In the interior of the Antarctic ice sheet, angle $u$ hardly varies. Under such circumstances, a small angle $v$ is preferred and the accurate estimation of flow direction is a prerequisite.

If the three-dimensional direction of the true flow is assumed and if a direction of the LOS displacement is not perpendicular to the glacier flow direction, the magnitude of the flow along this direction may be estimated. Furthermore, an algorithm of composing LOS measurements from two directions (e.g. ascending and descending orbits), with the assumption that ice flow is along the maximum slope (Joughin and others, 1998), is useful when more than one viewing direction is available.

For an ice sheet, the flow direction is dominated by the surface topography (slope and aspect), and using the DEM to determine the ice flow is straightforward. However, for ice flow on inland glaciers, especially those with widespread ice-free nunataks, the flow patterns are usually complicated (mostly in side-constrained forms) and the directions are hard to estimate. As for side-constrained ice flow, it is assumed that the horizontal component of flow direction is along the central line or parallel to its boundaries (Paterson, 1994).

The boundary of ice flow could be estimated from visual features in SAR amplitude or InSAR correlation products. In

\begin{tabular}{|c|c|c|c|c|c|c|}
\hline Satellite & Orbits & Pass dates & $\begin{array}{c}B_{\mathrm{n}} \\
\mathrm{m}\end{array}$ & $\begin{array}{c}\mathrm{HA} \\
\mathrm{m}\end{array}$ & $\begin{array}{l}\mathrm{SD} \\
\mathrm{cm}\end{array}$ & $\begin{array}{c}\text { Interval } \\
\text { days }\end{array}$ \\
\hline $\begin{array}{l}\text { ERS-1/-2 } \\
\text { IFRS-1 }\end{array}$ & $\begin{array}{l}23910 / 04237 \\
23844 / 24503\end{array}$ & 10/11 Feb. 1996 & 165 & 54 & 2.83 & 1 \\
\hline
\end{tabular}
SAR images, ice-flow stripes could sometimes be seen, and low-correlation areas in the correlation image usually indicate shear margins.

Table 1. ERS-1/-2 and JERS-1 data used for interferometric processing 


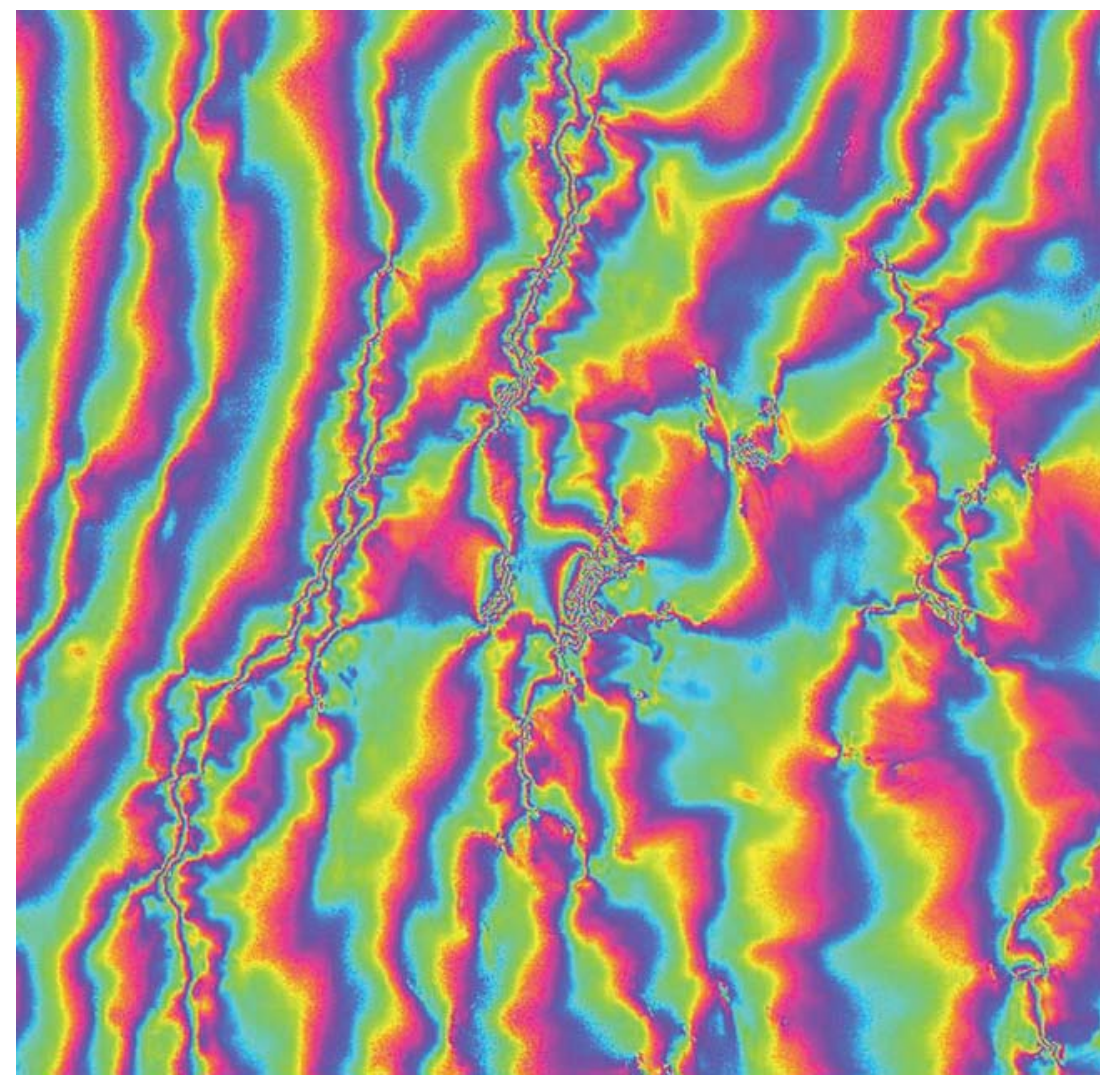

Fig. 3. Slant-range interferogram of ERS-1/-2 tandem pair. Flat-Earth phases were removed.

\section{Error analysis}

There are several error sources, including errors of spatial baseline, flow direction, residual flow phase in the DEM, atmospheric and ionospheric artifacts, and SAR penetration.

Baseline uncertainty, the main error source, has different effects on the topographic and displacement pairs. It leaves height trends in the generated DEM product from the ERS-1/-2 pair; while in the JERS-1 pair the uncertainty in baseline affects the magnitude of topography in the composite interferogram. Our attempts to reduce the baseline uncertainty include introducing DEOS (Delft Institute for Earth-oriented Space Research) precise orbit information and refining the baseline using ground-control points and the RAMP DEM for the ERS pair, and adopting a shorter baseline for the JERS-1 pair.

The error in flow direction is partly caused by the assumption of side-constrained ice flow, which is not valid everywhere. The miscalculation in flow direction thus affects the flow-speed estimate. For instance, when $v=20^{\circ}, \Delta v=5^{\circ}$ will cause a relative error of about $3 \%$ in the estimate of flow rate.

Considering only glacier motion for the tandem ERS pair, and assuming $v=0$, one fringe is equivalent to ice flow at about $24 \mathrm{~m} \mathrm{a}^{-1}$, so $8 \mathrm{~m} \mathrm{a}^{-1}$ is about $1 / 3$ of a fringe. This may be hard to see in the composite interferogram, but could be an error $(1 / 3(\mathrm{HA})=18 \mathrm{~m})$ for the DEM. Such an error is equivalent to about $1 / 19$ of a fringe in the JERS-1 pair, which is negligible.

Interferogram images may exhibit artifacts due to spatial and temporal variations of atmospheric water vapor. Other tropospheric variations, such as pressure and temperature, also induce distortions, but the effects are smaller in magnitude and more evenly distributed throughout the interferogram than the wet troposphere term. Since the atmospheric humidity is quite low on the Antarctic Plateau, these atmospheric artifacts can be ignored. lonospheric phenomena may also create local artifacts on interferograms especially on L-band InSAR, but these, too, were ignored in this research.

Another factor that might be considered for the proposed method is the different penetration of L-band and C-band radar waves in firn layers. InSAR topography generally closely follows the surface profile of ice sheets and glaciers (Bindschadler and others, 1999), yet the phase center of the radar data is typically located several meters below the surface. C-band penetration is small (1-2 m) on exposed ice, but up to $10 \mathrm{~m}$ on dry, cold firn. Penetration depth is $5-10 \mathrm{~m}$ greater for the L band, and up to $60-120 \mathrm{~m}$ on smooth, cold, exposed ice (Rignot and others, 2001). The operation of removing topographic effects from the JERS-1 interferogram using the ERS DEM causes a residual topographic height effect (3-8 m). However, this residual height is negligible for the $333 \mathrm{~m} \mathrm{HA}$ of the JERS-1 pair, since the corresponding phase is $<1 / 40$ of a fringe.

\section{RESULTS}

Since the ERS- $1 /-2$ pair has only 1 day separation, temporal decorrelation is minimal. The range direction of the selected descending JERS-1 SAR image is almost parallel to the overall ice-flow direction (Fig. 3), so the InSAR sensitivity to flow displacements is quite good. Furthermore, all the selected SAR data were acquired in 1996, so the combination is reasonable. 

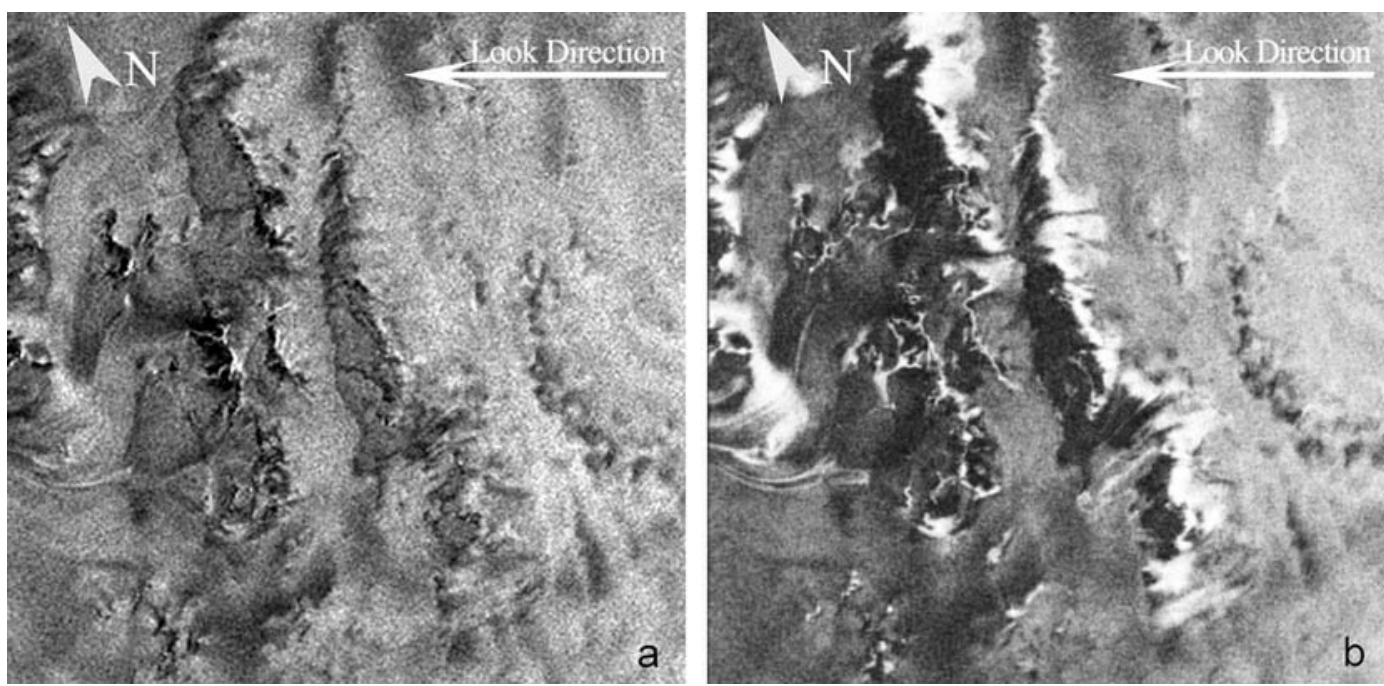

Fig. 4. SAR images used for co-registration: (a) ERS-1 SAR taken 10 February 1996. (b) JERS-1 SAR taken 21 June 1996. (ERS-1 image (C) European Space Agency 1996 and JERS-1 image (C) National Space Development Agency of Japan (NASDA) 1996.)

\section{ERS DEM}

The software used for InSAR processing is EarthView ${ }^{\circledR}$ InSAR v2.1.2, developed by Atlantis Scientific Inc. The precise ERS orbits from DEOS are adopted for baseline determination. Radial errors of individual precise orbits are estimated to be approximately $50 \mathrm{~mm}$ (Scharroo and Visser, 1998). Since the reliability of precise orbits is not well known over parts of Antarctica, the RAMP DEM is used for baseline refinement.

The flattened and enhanced slant-range interferogram of the ERS tandem pair is given in Figure 4. For this tandem pair, the height ambiguity is about $54 \mathrm{~m}$. Fringes extending from left to right (in the color order red-green-blue) indicate the continuous decrease of surface elevation along a slope. There are nunataks and mountains in the central section of the image, where dense and discontinuous fringes are seen. These result from the side-looking geometry of the SAR system and the steep nunatak surface. The layover effect and high topographic phase gradient make it difficult to phaseunwrap in most ice-free nunatak regions, and this introduced a height error in these regions. However, this does not affect the following differential processing, since no glacier motion occurs at the nunataks.

The GPS DEM of the core region was used to calibrate and correct the InSAR DEM product. The final DEM result is in a Universal Transverse Mercator projection (zone 43C) with a grid size of $30 \mathrm{~m}$.

\section{Differential result}

The steps for generating a differential result are coregistration, interferogram generation, phase unwrapping and finally generation of the DInSAR result from the phase. It is obvious that precise co-registration is most important. To achieve this, two images are needed. The JERS-1 master image is used for reference and for the second we have two choices: one is the simulated SAR image from the ERS DEM and the other is the SAR image from the ERS pair.

The simulated SAR image differs significantly from a normal SAR image, especially in the featureless ice surface, which makes co-registration difficult. However, it is also challenging to co-register SAR images acquired at different bands ( $\mathrm{L}$ and $\mathrm{C})$, incidence angle $\left(38^{\circ}\right.$ vs $\left.23^{\circ}\right)$ and polarization (VV vs $\mathrm{HH}$ ).

The JERS-1 and ERS-1 SAR images selected for coregistration are illustrated in Figure 3. The appearance of the two images differs significantly, especially in the nunatak regions. The right side of the mountains, which directly faces the SAR sensor, usually appears much brighter while the other side appears darker in the JERS- 1 than in the ERS- 1 image. The larger incidence angle, deeper penetration and stronger volume scattering of JERS-1 SAR leads to stronger corner-reflector effects on the side facing the sensor, and a high shadowing effect on the opposite side. The glacier surface beyond the nunataks looks almost the same in JERS-1 and ERS-1 images, for instance in the right portion of the images.

High-quality co-registration can be achieved by having sufficient tie points. However, in this case, the number of tie points automatically generated by the EarthView ${ }^{\circledR}$ InSAR program is insufficient; extra tie points were identified and input manually. The ERS DEM was used to co-register the images and remove terrain distortion.

The resulting differential interferogram superimposed on TM imagery is shown in Figure 5. From the underlying TM imagery, we could interpret many of the glacial features. The nunataks (e.g. Wilson Ridge, Mount Harding, Zakharoff Ridge and Davey Nunataks) and mountains (Gale Escarpment) extend from north to south, which impedes the movement of glacier ice towards Lambert Glacier. However, the nunataks are separated and the mountain ridge of Gale Escarpment is divided into three parts (north, middle and south) with two low-elevation gaps. Surface elevation decreases from right to left.

The glacier flow pattern is quite complicated. As we can see in Figure 5, the ice-sheet flow is divided by the three portions of Gale Escarpment. Two concentric fringes, marked as $A$ and $B$, are present in the nunataks region, which indicate two ice-flow branches. They run downstream and join together at $\mathrm{C}$. Outside the nunataks and to the north and south, glacier flow is less restricted, and dense fringes (high phase gradient) indicate shear margin regions bounding the range. 


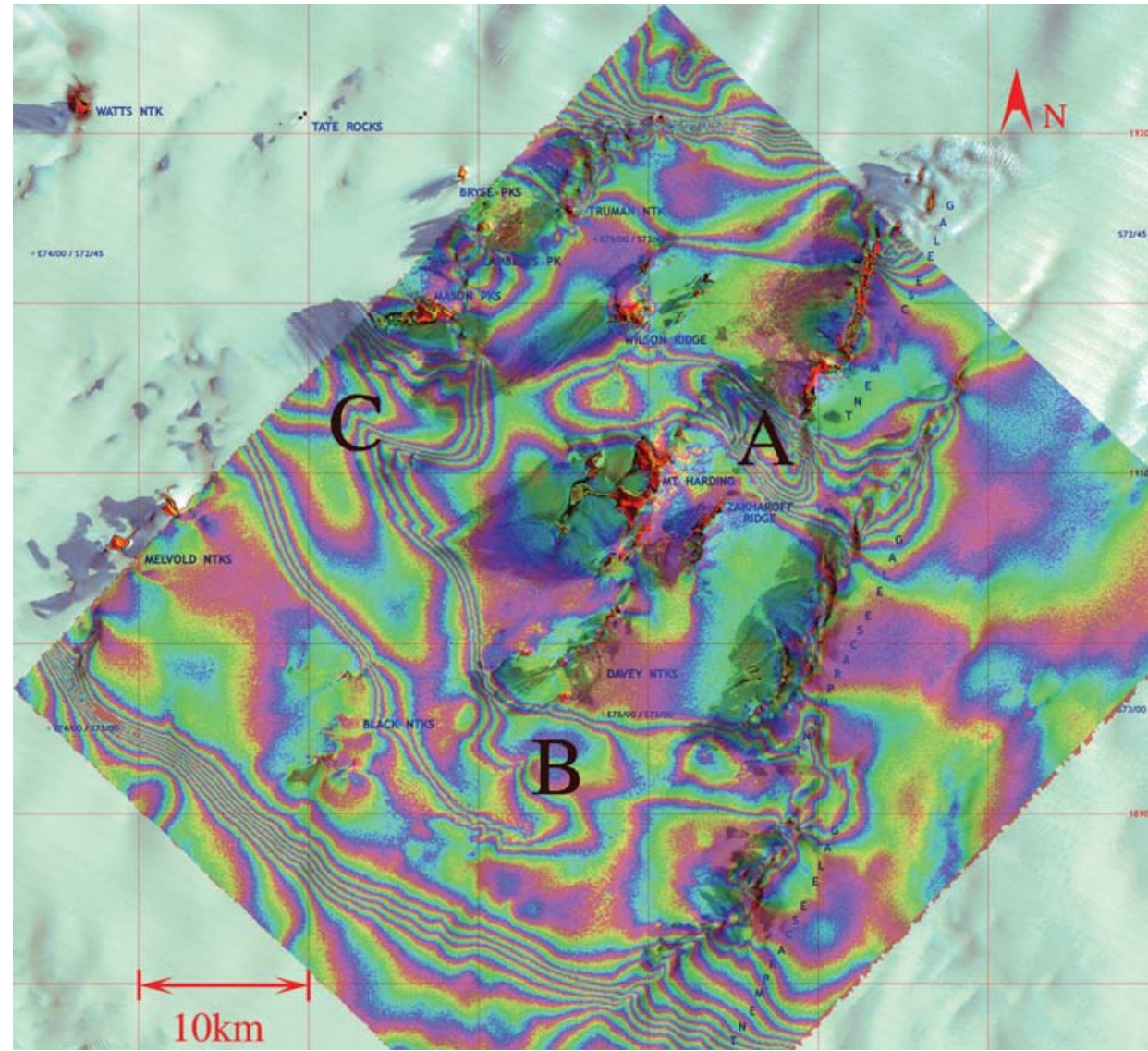

Fig. 5. Ice flow in JERS-1 differential interferogram (the whole scene). Nunataks and mountains are in bright red. The ice branches marked as $\mathrm{A}$ and $\mathrm{B}$ curve among the nunataks and join together at $\mathrm{C}$.

A subscene of the study area, 'region $A^{\prime}$, is investigated further (Fig. 6). Mount Harding and Zakharoff Ridge are on the lower left, and Wilson Ridge lies to the north of Mount Harding. On the right is the northern gap of the Gale Escarpment. Glacier flow curves among the gaps between separated nunataks, as seen from the concentric fringes. There is no visible fringe between Gale Escarpment (middle) and Zakharoff Ridge, which means little or no motion occurs here. The densities of the fringes are much larger along the boundaries of the glacier, which indicates shear zones where flow changes rapidly. Field expeditions report that crevasses are widespread here.

\section{Ice-flow field}

The glacier center line, with four tangential vectors indicating the flow direction, is shown in Figure 6. The angle between the vector and the look direction of SAR is $v$ (see Fig. 2). Of the four sites (a-d), the value of $v$ is largest at $d$, where InSAR is the least sensitive to glacier flow. The much sparser fringe at $d$ is coincident with that.

Calculating from the ERS DEM, the average slope along the center line is $<2.5^{\circ}$. Therefore, ice flow is assumed to be horizontal for simplicity. In order to obtain the absolute flow velocities, one or more ground points with known flow velocities are needed. Since no in situ flow measurements have been taken in this area, we work outward from the fixed nunataks.

The ice is generally taken to move at constant velocity in inland Antarctica (that is, without seasonal variations), so the measured glacier displacement during the 44 day JERS-1 cycle is used to calculate the annual displacement. Using Mount Harding as zero reference, the peak of phase fringes is about five rings near site $b$. Each circle denotes a LOS displacement of $11.75 \mathrm{~cm}$, so the horizontal flow velocity at site $b$ is about $7.91 \mathrm{~m} \mathrm{a}^{-1}$.

After phase unwrapping, the slant-range change product is generated. Based on a grid-based $(3 \times 3)$ algorithm, the change value is multiplied by the transformation coefficients calculated from the aspect of ice flow and the local incidence angle of the SAR system on each gridpoint. The resulting grid file contains information on both flow direction and flow speed.

The ice-flow field of the Grove Mountains is illustrated in Figure 7. The AMM RADARSAT mosaic of the area is set as the background, over which is laid the composite of TM imagery and differential interferogram. The uppermost layer is the ice-flow vectors (indicated as arrows).

The maximum flow rates of the two branches that curve inside the nunatak region are about $8 \mathrm{ma}^{-1}$, while the velocities are $>10 \mathrm{ma}^{-1}$ where ice flow is outside the nunataks region and, thus, less obstructed.

The available flow velocity results given by other methods are introduced for comparison and interpretation.

Using the method of speckle matching and interferometry with 24 day repeat-pass RADARSAT imagery acquired in 2000, Joughin (2002) estimated the ice-flow field of the whole Lambert Glacier-Amery Ice Shelf. From the resultant image, the ice flow in this region is about $10 \mathrm{~m} \mathrm{a}^{-1}$. Beside that, about $60 \mathrm{~km}$ east of the research area, along the Chinese and Australian inland traverse route, 


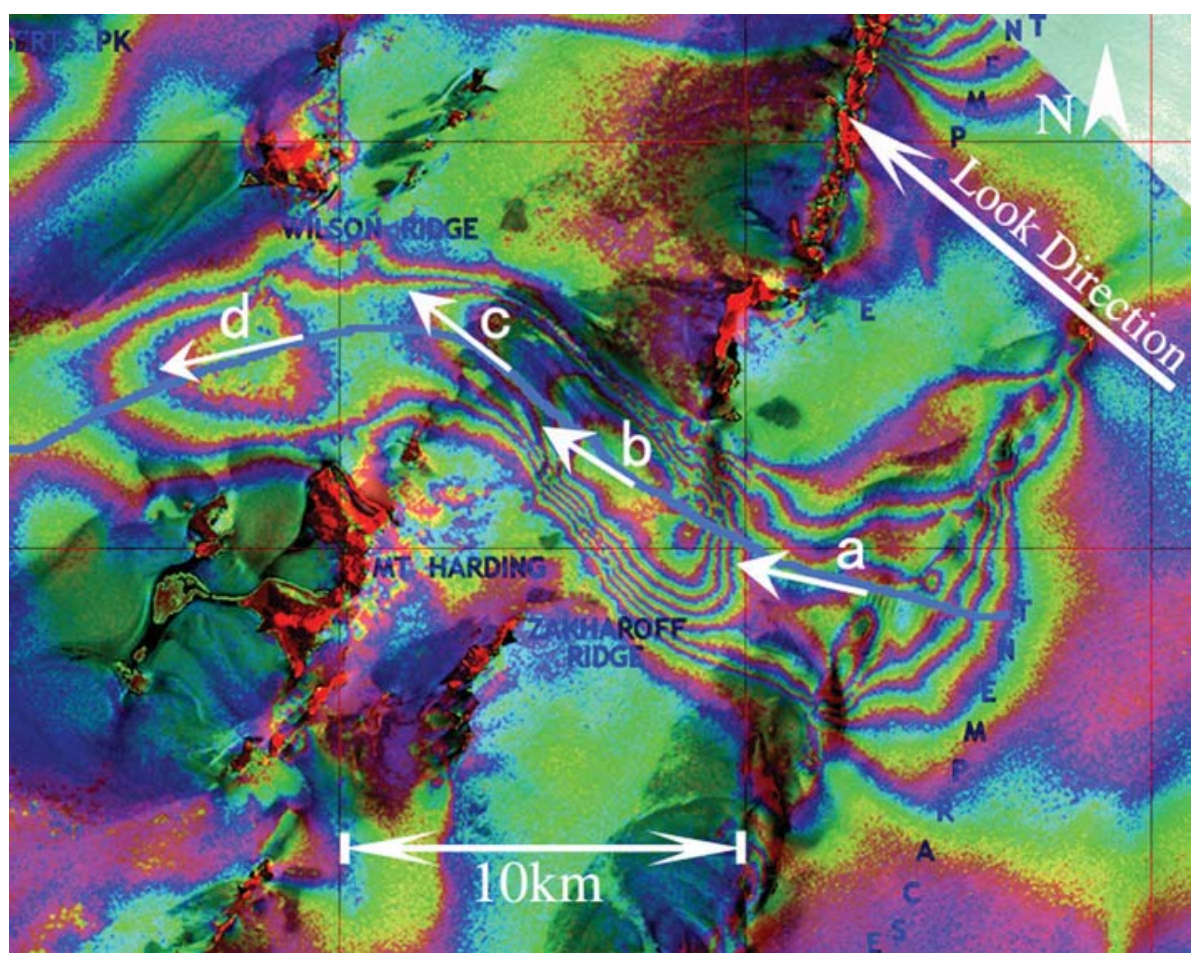

Fig. 6. Ice flow in JERS-1 interferogram (region A). The look direction of SAR is marked. The overall flow direction of the glacier is from right (east) to left (west).

scientists measured the flow velocities by repeating GPS observations on established poles (Manson and others, 2000; Wang and others, 2001). The coordinates and flow rates of seven GPS points east of the Grove Mountains are given in Table 2. They are also marked in Figure 7. The distribution of the seven flow vectors and pattern of flow stripes surrounding the nunataks region as seen in background SAR imagery indicate the obstructing effect of the Grove Mountains on ice flow. At four sites (LGB61, DT063, LGB60 and DT085) just upstream of the Grove Mountains, the flow rates are around $8 \mathrm{ma}^{-1}$. This is coincident with the maximum flow rates amidst the nunatak groups revealed by DInSAR. Flow rates at the other three sites (DT038, LGB62 and LGB59) are greater; at DT038 and LGB62, the flow rates exceed $20 \mathrm{~m} \mathrm{a}^{-1}$.

The RAMP result and the GPS-surveyed flow rates indicate that the DInSAR results are reasonable, and that the integrated four-pass DInSAR using JERS- 1 and ERS-1/-2 data is a good method for complex inland ice flow.

Table 2. Horizontal flow rates at the GPS sites east of Grove Mountains

\begin{tabular}{|c|c|c|c|c|c|}
\hline Point & $\begin{array}{l}\text { Latitude } \\
{ }^{\circ} \mathrm{S}\end{array}$ & $\begin{array}{c}\text { Longitude } \\
{ }^{\circ} \mathrm{E}\end{array}$ & $\begin{array}{l}\text { Velocity } \\
\mathrm{m} \mathrm{a}^{-1}\end{array}$ & Azimuth & Surveyor \\
\hline DT038 & -72.54194 & 77.5872 & 20.9 & 306 & $\mathrm{CHN}$ \\
\hline LGB62 & -72.671167 & 77.4935 & 21.3 & 306 & AUS \\
\hline LGB61 & -72.931167 & 77.263167 & 8.6 & 310 & AUS \\
\hline DT063 & -72.98139 & 77.29 & 8.4 & 308 & $\mathrm{CHN}$ \\
\hline LGB60 & -73.191333 & 77.026833 & 7.6 & 265 & AUS \\
\hline DT085 & -73.3675 & 77.015 & 8.2 & 268 & $\mathrm{CHN}$ \\
\hline LGB59 & -73.452 & 76.78767 & 10.6 & 276 & AUS \\
\hline
\end{tabular}

\section{CONCLUSION AND DISCUSSION}

The integration of JERS- 1 and ERS SAR data in differential interferometry for the measurement of complex glacier motion has been described and the ERS tandem data together with a JERS-1 data pair were used to assess performance in the Grove Mountains area. Synoptic icesurface velocities in the Grove Mountains were obtained by unwrapping and geometrically correcting interferometric fringes derived from the differential JERS-1 SAR interferogram, in spite of less accurate orbit information than ERS-1/-2 SAR.

The flow rates exceed $10 \mathrm{ma}^{-1}$ outside the nunataks region. Two glacier branches are present within the nunataks group and have a lower velocity (about $8 \mathrm{~m} \mathrm{a}^{-1}$ ), which is associated with subglacial valleys and gaps between nunataks and mountains.

The remarkable advantages of L-band InSAR are (1) high coherence over long periods; (2) the fact that it is less sensitive to topography than C-band; and (3) appropriate sensitivity to flow displacement. The potential for the investigation of the pattern of complex motion over inland glaciers at very high levels of resolution in time and space is clear, and is likely to reveal an increasing diversity of flow regimes and motion events. This approach is expected to expand JERS-1 InSAR applications in Antarctica.

Further work includes error removal, generation of iceflow fields over wider areas and integrated analysis with subglacial bathymetric measurements.

\section{ACKNOWLEDGEMENTS}

This investigation is fully supported by the Knowledge Innovation Program of the Chinese Academy of Sciences (CAS; CX020006). Special thanks go to Xiaowen Li (Director of the Institute of Remote Sensing Applications, CAS) and 


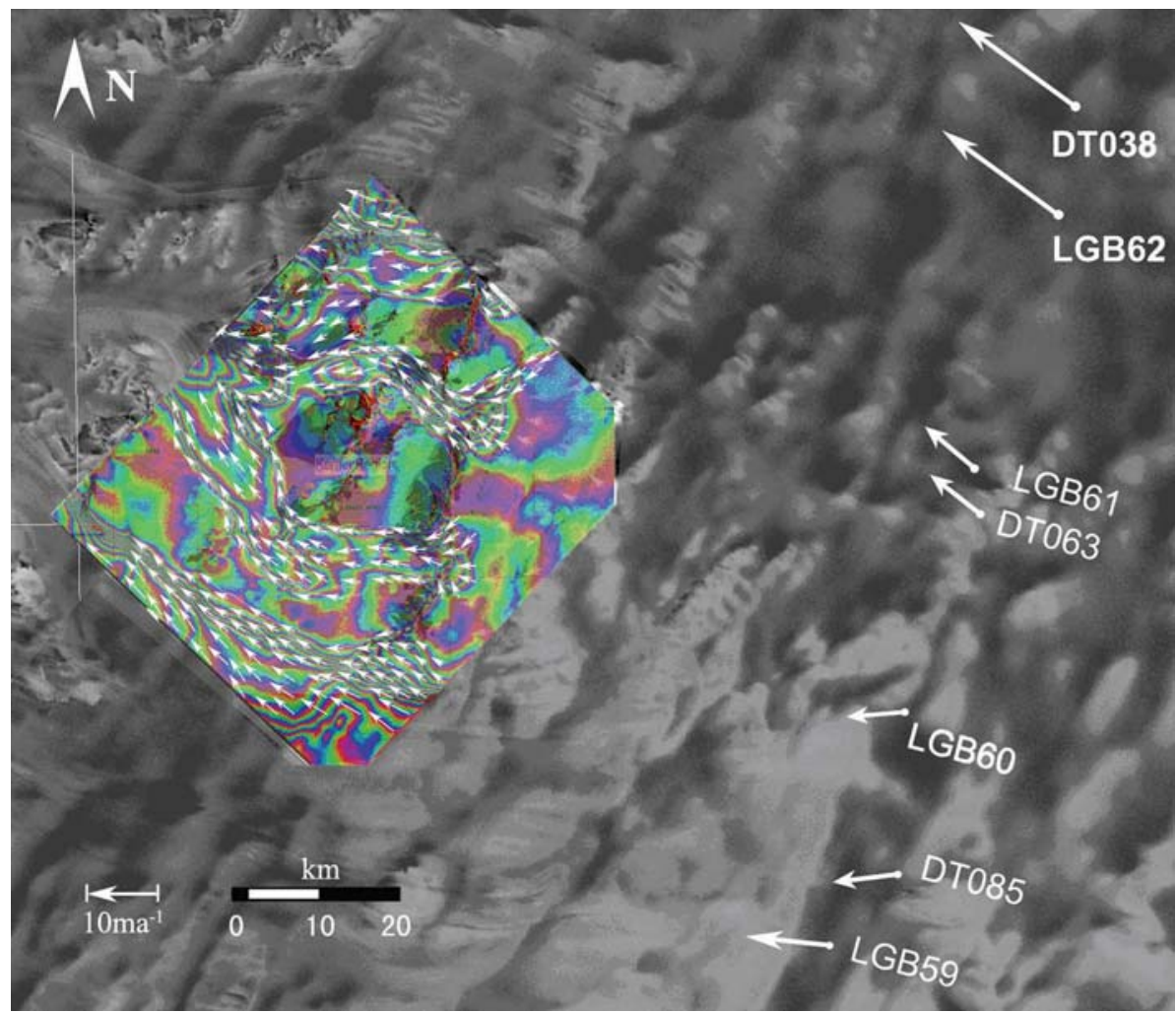

Fig. 7. Flow velocity map in the Grove Mountains. The lower-left arrow mark is a referential length of the flow vector at $10 \mathrm{ma}^{-1}$. The background image is from the AMM RADARSAT mosaic.

Peng Gong (Director of the State Key Laboratory of Remote Sensing Science) for encouraging this work. The authors thank T.A. Scambos, I. Joughin and D.R. Fatland for useful suggestions and comments that helped improve the manuscript. The ERS SAR data were made available by the ESA under the VECTRA AO Project. The JERS-1 data were provided by NASDA.

\section{REFERENCES}

Alberts, F.G., ed. 1995. Geographic names of the Antarctic. Second edition. Washington, DC, National Science Foundation.

Anja, P. and 7 others. 2004. Tides in the subglacial Lake Vostok, East Antarctica. In Proceedings of the 'Fringe 2003' Workshop. Frascati, European Space Agency. CD-ROM.

Bindschadler, R. 1998. Monitoring ice sheet behavior from space. Rev. Geophys., 36(1), 79-104.

Bindschadler, R.A., M. Fahnestock and A. Sigmund. 1999. Comparison of Greenland Ice Sheet topography measured by TOPSAR and airborne laser altimetry. IEEE T. Geosci. Remote, 37(5), 2530-2535.

Cumming, I., J.L. Valero, P.W. Vachon, K. Mattar, D. Geudtner and L. Gray. 1997. Glacier flow measurements with ERS tandem mission data. In Proceedings of the 'Fringe 96' Workshop on ERS SAR Interferometry. Noordwijk, European Space Agency, 353-362.

Goldstein, R.M., H. Engelhardt, B. Kamb and R.M. Frolich. 1993. Satellite radar interferometry for monitoring ice sheet motion: application to an Antarctic ice stream. Science, 262(5139), 1525-1530.

Gray, A.L., K.E. Mattar and P.W. Vachon. 1998. InSAR results from the RADARSAT Antarctic Mapping Mission data: estimation of data using a simple registration procedure. In Stein, T., ed. Proceedings of the 18th International Geoscience and Remote Sensing Symposium (IGARSS 1998), July 6-10, 1998.
Piscataway, NJ, Institute of Electrical and Electronics Engineers, 1638-1640.

Hanssen, R.F. 2001. Radar interferometry: data interpretation and error analysis. Dordrecht, etc., Kluwer Academic Publishers.

Jezek, K.C. 2002. RADARSAT-1 Antarctic Mapping Project: changedetection and surface velocity campaign. Ann. Glaciol., 34, 263-268.

Joughin, I. 2002. Ice-sheet velocity mapping: a combined interferometric and speckle-tracking approach. Ann. Glaciol., 34, 195-201.

Joughin, I.R., D.P. Winebrenner and M.A. Fahnestock. 1995. Observations of ice-sheet motion in Greenland using satellite radar interferometry. Geophys. Res. Lett., 22(5), 571-574.

Joughin, I., R. Kwok and M. Fahnestock. 1996. Estimation of icesheet motion using satellite radar interferometry: method and error analysis with application to Humboldt Glacier, Greenland. J. Glaciol., 42(142), 564-575.

Joughin, I.R., R. Kwok and M.A. Fahnestock. 1998. Interferometric estimation of three-dimensional ice-flow using ascending and descending passes. IEEE T. Geosci. Remote, 36(1), 25-37.

Joughin, I. and 7 others. 1999. Tributaries of West Antarctic ice streams revealed by RADARSAT interferometry. Science, 286(5438), 283-286.

Kwok, R. and M.A. Fahnestock. 1996. Ice sheet motion and topography from radar interferometry. IEEE T. Geosci. Remote, 34(1), 189-200.

Kwok, R., M.J. Siegert and F.D. Carsey. 2000. Ice motion over Lake Vostok, Antarctica: constraints on inferences regarding the accreted ice. J. Glaciol., 46(155), 689-694.

Manson, R., R. Coleman, P. Morgan and M. King. 2000. Ice velocities of the Lambert Glacier from static GPS observations. Earth Planets Space, 52(11), 1031-1036.

Mattar, K.E., P.W. Vachon, D. Geudtner, A.L. Gray, I.G. Cumming and M. Brugman. 1998. Validation of alpine glacier velocity measurements using ERS tandem-mission SAR data. IEEE T. Geosci. Remote, 36(3), 974-984. 
Ozawa, T., K. Doi and K. Shibuya. 1999. A case study of generating a digital elevation model for the Soya coast area, Antarctica, using JERS-1 SAR interferometry. Polar Geoscience, 12, 227-239.

Paterson, W.S.B. 1994. The physics of glaciers. Third edition. Oxford, etc., Elsevier.

Rignot, E., K. Echelmeyer and W. Krabill. 2001. Penetration depth of interferometric synthetic-aperture radar signals in snow and ice. Geophys. Res. Lett., 28(18), 3501-3504.

Scambos, T.A. and R. Bindschadler. 1993. Complex ice-stream flow revealed by sequential satellite imagery. Ann. Glaciol., 17, 177-182.

Scambos, T.A., M.J. Dutkiewicz, J.C. Wilson and R.A. Bindschadler. 1992. Application of image cross-correlation to the measurement of glacier velocity using satellite image data. Remote Sens. Environ., 42(3), 177-186.
Scharroo, R. and P. Visser. 1998. Precise orbit determination and gravity field improvement for the ERS satellites. J. Geophys. Res., 103(C4), 8113-8127.

Wang, Q.H., D.C. E and C.M. Chen. 2001. Antarctic traverses from Zhongshan Station to Dome-A and the results analysis for the GPS points along the expedition route. Geo-Spatial Information Science, 5(1), 31-36.

Wangensteen, B., D.J. Weydahl and J.O. Hagen. 1999. Mapping glacier velocities at Spitsbergen using ERS tandem SAR data. In Proceedings of International Geoscience and Remote Sensing Symposium (IGARSS 1999), 28 June-2 July, 1999. Piscataway, NJ: Institute of Electrical and Electronics Engineers, 1954-1956. Young, N.W. and G. Hyland. 2002. Velocity and strain rates derived from InSAR analysis over the Amery Ice Shelf, East Antarctica. Ann. Glaciol., 34, 228-234.

MS received 26 November 2004 and accepted in revised form 22 October 2005 